\title{
Bioindicators and biomonitoring: honeybees and hive products as pollution impact assessment tools for the Mediterranean area
}

\author{
Stefano Girotti ${ }^{1}(1) \cdot$ Severino Ghini ${ }^{1} \cdot$ Elida Ferri $^{1} \cdot$ Luca Bolelli $^{1} \cdot$ Roberto Colombo $^{2} \cdot$ Giorgia Serra $^{2}$. \\ Claudio Porrini $^{3}$. Stefano Sangiorgi ${ }^{1}$
}

Received: 1 May 2020 / Accepted: 18 September 2020 / Published online: 13 October 2020

(c) The Author(s) 2020

\begin{abstract}
The global range of the environmental quality issues we all face necessitates integrated action from all of the countries that suffer from a particular environmental issue. We must be able to obtain data on the presence of pollutants and their effects on biota from any territory, regardless of its environmental, infrastructural, social, and economic conditions. Biomonitoring utilizes organisms and natural materials to obtain this information. In particular, the honeybee is a ubiquitous, easy-to-breed organism with great mobility. Its body, which is covered with hairs, picks up materials and particulates that it encounters in the environment. Therefore, bees are highly effective accumulators of materials from the soil, vegetation, air, and water. These characteristics mean that the honeybee is both a bioindicator and a passive bioaccumulator organism, making it an ideal agent for easily monitoring vast areas inexpensively, even in regions where infrastructure is scarce. In this short review, we summarize the main targets of the honeybee-based monitoring campaigns that have been carried out to date, highlighting the results obtained in assessments of organic and inorganic pollution performed by coupling more modern technologies with this long-standing practice. It is hoped that this review will make scientists more aware of the incredible potential of these delicate organisms to provide data that could prove useful in the management of environmental issues.
\end{abstract}

Keywords Bioindicators $\cdot$ Environmental monitoring $\cdot$ Honeybees $\cdot$ Pesticides $\cdot$ Heavy metals $\cdot$ Organic pollutants · Radionuclides

\section{Environmental biomonitoring}

Widespread anthropization and various human activities are degrading the environment with increasing intensity. Our awareness of the incalculable damage, including serious diseases, caused by continually discharging chemicals into

Communicated by Mohamed Ksibi, Co-Editor in Chief.

This paper was selected from the 2nd Euro-Mediterranean Conference for Environmental Integration (EMCEI), Tunisia 2019.

Stefano Girotti

stefano.girotti@unibo.it

1 Department of Pharmacy and Biotechnology, University of Bologna, Via San Donato 15, 40127 Bologna, Italy

2 Agricultural Research and Economy Council, Bologna Research Centre, Bologna, Italy

3 Department of Agroenvironmental Science and Technology, University of Bologna, Via G. Fanin 42, 40127 Bologna, Italy the environment has grown considerably over the last few decades, especially in relation to persistent and accumulating pollutants. Nevertheless, the number of toxicants that have been released into the environment is now very large, and only a tiny fraction of those substances are regularly monitored. In recent decades, environmental directives have lowered the permitted levels of pollutants in water, the air, and foods, and have lengthened the list of chemicals that are banned and need to be assessed (US EPA 1970, 1978, 2016; EU 2000, 2008a, b, 2010, 2015, 2018; POPRC 2016). Due to the unquestionable importance of aquatic resources, the conservation and sustainable management of aquatic ecosystems is a priority in environmental programs worldwide. Similarly, air pollution is a serious global problem that threatens ecosystems as well as human health and life (US EPA 1974, 2000). Air contaminants reach the soil and water bodies where they-together with the xenobiotics employed in intensive agricultural activities - can enter the food chain, producing further damage (EU 2008b). 
One of the main challenges in contamination surveillance is to comprehensively characterize and evaluate the impacts of the presence of a complex mixture of pollutants on the environment. New monitoring and analytical methods that exploit the most advanced technologies are continuously being developed and validated as possible tools for performing this highly demanding analysis (Ma et al. 2020; Ye et al. 2020; Ramachandaran et al. 2019; Li et al. 2019; Rasheed et al. 2019; Shi et al. 2019; Hernandez et al. 2019; Horne et al. 2020). Nevertheless, the quali-quantitative determination of xenobiotics is only part of the information needed to implement an accurate risk assessment.

Environmental pollution can be evaluated directly by applying a specific sampling method, transporting the resulting samples to the laboratory, and then analyzing them with a precise analytical procedure. These active procedures are accurate and efficient but involve various drawbacks. The concentration of a pollutant varies spatiotemporally, especially in air. Any pollution monitoring program should therefore be statistical in nature, and should include a high density of sampling points to guarantee representative results. However, establishing an array of monitoring instruments in the field is sometimes difficult due, for instance, to high equipment costs, the need to supply power to the device, and the requirement for attended operation. All of these factors can strongly limit the sampling point density, meaning that the resulting data can have low statistical value.

The development of passive sampling techniques based on free analyte flow from the environment to a collecting medium has yielded low-tech, low-maintenance, and costeffective methods for environmental monitoring that do not require a power source. Nevertheless, passive techniques based on substance capture by membranes or polymers cannot detect short-term variations in pollutant concentrations or environmental conditions, and they can present calibration problems (Lai et al. 2019).

Passive sampling methods can also utilize biological species (organisms and materials) that can act as reliable sensors of pollutants in their habitats; this approach to environmental contamination surveillance is called "biomonitoring" (Butterworth et al. 1995; Wolterbeek 2002). Effect-based methods such as bioassays and biomarkers are essential tools for implementing monitoring strategies. The utility of living organisms as indicators of environmental quality has long been widely recognized, since-in contrast to chemical analysis - they can be used to directly examine the effects of pollutants on the biosphere. Over the past few decades, various plants, animals, fungi, and bacteria have been employed as effective bioindicators and biomonitors in air, soil, and water pollution surveys (Butterworth et al. 1995; Wolterbeek 2002; Al-Alam et al. 2019; Devillers and Pham-Delegue 2002; Asif et al. 2018; Panichev and McCrindle 2004;
Storelli and Marcotrigiano 2005; Mahapatra et al. 2019; Van Meter et al. 2019).

Biomonitoring can also be classified into passive and active techniques. Passive biomonitoring is the observation and analysis of organisms that are indigenous to the ecosystem, whereas active biomonitoring involves the insertion (under controlled conditions) of organisms into the site to be monitored. Biomonitoring allows detailed and reliable coverage of a wide territory at relatively low cost-definitely lower than the cost of maintaining electronic monitoring stations. Moreover, the data obtained by biomonitoring are not comparable to that provided by a single sampling instrument, since a biomonitoring dataset provides information on the responses of a wide range of living organisms in the surveyed area to contaminants. Also, any instrumental or analytical chemistry measurement technique can be used to extract biomonitoring data. These advantages of biomonitoring make this approach to environmental contamination surveillance very useful.

Biomonitoring can employ sensitive or accumulative organisms: bioindicators or bioaccumulators, respectively (Wolterbeek 2002). Bioindicators display very high sensitivities to pollutants. They respond to the quality of the environment under examination by undergoing morphological and/or physiological changes, such as photosynthetic or respiratory activity modifications (Butterworth et al. 1995; Al-Alam et al. 2019; Batzias and Siontorou 2007). According to the US Environmental Protection Agency report on the environment (US EPA 2007), the key criteria for identifying a useful bioindicator are as follows:

- The indicator is useful, objective, reliable, and reproducible

- The underlying data are characterized by reliable collection methodologies, data management systems, and quality assurance procedures

- The data obtained can be used to derive changes or trends, are comparable across time and space, and are representative of the target population.

An organism must also have the following characteristics to be able to act as a bioindicator:

- Easily identified and easily sampled

- Is widespead in the studied area and has low mobility

- Has a long life cycle and shows high genetic uniformity across the studied area

- Is present in the studied area all year long.

Bioindicators permit the establishment of a network of monitoring sites with satisfactory coverage of the territory of interest. They do not require sophisticated and expensive equipment, an electricity supply, or specialized personnel. 
They allow a region to be probed for structural damage (either reversible or permanent) and to be monitored for any decrease in biotic diversity, i.e., a decrease in the number of species in the community along with a parallel increase in the number of individuals belonging to the more resistant species. The information they have supplied has raised our awareness of the effects of environmental pollution. Thus, the availability of a large number of reliable bioindicator species is an important step towards the wider application of this methodology.

An organism is defined as a bioaccumulator when it stores contaminants in its tissues. Bioaccumulation is an equilibrium process in which the bioaccumulator takes in and discharges substances from and into the surrounding environment. The mode of deposition of a pollutant in the environment can be inferred from its concentration in the bioaccumulator organism.

The disadvantages of some bioaccumulation techniques include the need for complicated analytical equipment and a detailed understanding of the taxonomy of one or more groups of organisms. Moreover, cumulative effects cannot be used to inform short-term decision-making and compensatory actions (Batzias and Siontorou 2007). When the pollutant is also a substance or an element that is present in the bioaccumulator naturally, it is necessary to assess the background value of that chemical by analyzing a blank (i.e., the same bioaccumulator but from an unpolluted area).

Some organisms that are typical of the environment under study can act as both a biosensor and a bioaccumulator; this is the case for honeybees.

\section{Honeybees and hive products as bioindicators and bioaccumulators of environmental pollution}

Worldwide, the genus Apis (honeybees) includes several species (see Table 1). The most well-known species of honeybee are those raised to produce honey and enhance the pollination. All honeybees organize themselves into societies that include both sexes. Females show morphological and physiological differences according to their specific roles.

The honeybee (Apis mellifera $\mathrm{L}$.) has proven to be a good biological indicator that is easy to use for environmental biomonitoring at any scale (Porrini et al. 2002). Honeybeebased biomonitoring is currently performed in many Mediterranean countries, such as Spain (Gutiérrez et al. 2015), Italy (Perugini et al. 2018), Croatia (Barišić et al. 2002), France (Badiou-Beneteau et al. 2013; Cotton et al. 2014), Greece (Kasiotis et al. 2014), Turkey (Yarsan et al. 2007), Iran (Sadegh et al. 2012), and Egypt (Malhat et al. 2015), as the favorable Mediterranean climate allows honeybee activity to be exploited for most of the year.

This organism is easy to breed, almost ubiquitous, and has modest food requirements. Its very high rate of reproduction and relatively short average lifespan causes honeybee colonies to undergo rapid, continuous regeneration, which plays a fundamental role in colony survival. These organisms do not accumulate and retain pollutants in their tissues for long periods; they transfer the compounds they collect to their products, such as honey, which is also used as a biomonitoring tool. The high mobility and wide flying range of honeybees allow a vast area to be monitored using these insects. The honeybee body is covered with hairs, which make it particularly suitable for capturing the particulate materials they encounter during their interactions with the environment.

Table 1 Important species of Apis Linnaeus, 1758

\begin{tabular}{lll}
\hline Apis Linnaeus, 1758 species & Geographical distribution & Nest structure \\
\hline Apis mellifera Linnaeus, 1758 & Originally Europe, but now all over the world & Honeycombs within buried cavities \\
Apis mellifera ligustica Spinola, 1806 & Italy & Single honeycomb \\
Apis andreniformis Smith, 1858 & Thailand, Vietnam, and Malaysia & Honeycombs on open-air rocks \\
Apis laboriosa F.Smith, 1871 & Nepal, Laos, and China & Honeycombs within buried cavities \\
Apis nigrocincta Smith, 1861 & Indonesia & Honeycombs within buried cavities \\
Apis cerana Fabricius, 1793 & Russia, New Guinea & Honeycombs on protruding rocks \\
Apis dorsata Fabricius, 1793 & India and Indonesia & Single honeycomb \\
Apis florea Fabricius, 1787 & Southeastern Asia & Honeycombs within buried cavities \\
Apis cerana nuluensis Tingek, Koeniger \& Koeniger, & Borneo & Honeycombs within buried cavities \\
1996 & & Sumatra and Java \\
Apis vechti (Maa, 1953) & &
\end{tabular}


Fig. 1 Honeybees can capture pollutants that are in the air, deposited on plant surfaces and flowers, in the soil, and dissolved in water

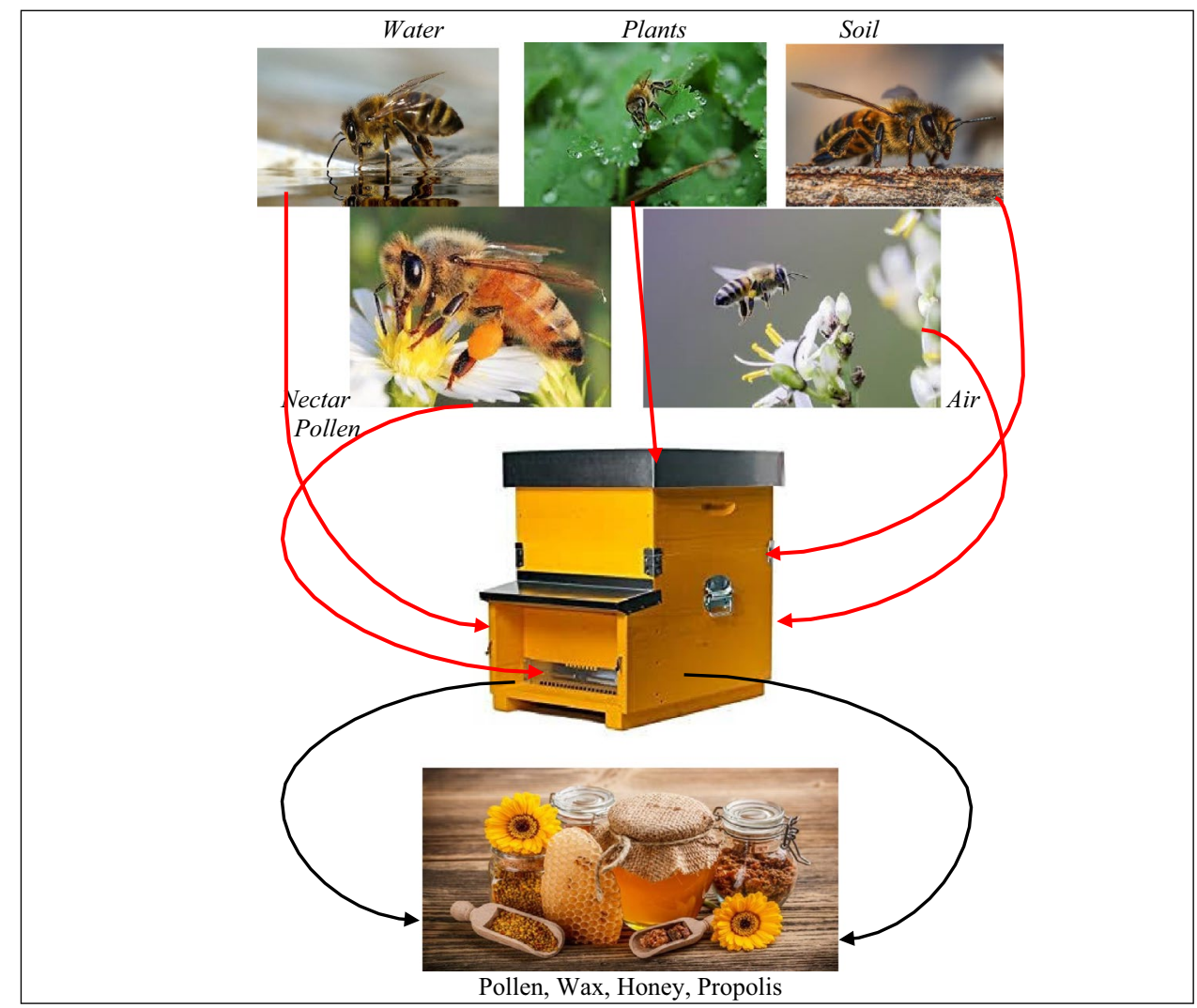

Honeybees are a highly efficient means of performing ground surveys (they make numerous inspections per day), and the majority of their flights are within $2 \mathrm{~km}$ of their colony. They visit almost all environmental sectors (soil, vegetation, water, and air) within a circular area with a radius of approximately $12 \mathrm{~km}^{2}$ around the hive, providing numerous randomly collected samples. They gather nectar, pollen, honeydew, propolis, and water, all of which are brought into the hive and stored there according to verifiable criteria. Once in the hive, these products are easy to sample and subsequently analyze for contaminants (i.e., the bees act as bioaccumulators) (see Fig. 1).

On the other hand, honeybees are highly sensitive to most agrochemicals. Bee mortality can greatly increase in the presence of certain highly toxic compounds, which immediately highlights the forbidden spread of such chemicals throughout the environment (e.g., during flowering, in the presence of wild blooms, during windy days, etc.). Physiological modifications can appear in bees after they have ingested less toxic pollutants, which can be identified by chemical and biochemical analyses (i.e., the bees act as biosensors). Hence, bees can be used to detect chemical impairment of their habitat by studying various endpoints: mortality (in the case of pesticides to which they are very sensitive); physiological, biochemical, or behavioral changes; and the response of the population distribution to sublethal pollutant toxicity (Dolores Hernando et al. 2018). The levels of residues on or within their bodies and the contamination of beehive products reflect the pollutant content of their environment (Porrini et al. 2002; Badiou-Beneteau et al. 2013; Codling et al. 2016; Cousin et al. 2019; Drummond et al. 2017; El-Saad et al. 2017; Hernandez et al. 2019).

Note that, henceforth, when we mention "honeybees," we are referring specifically to worker bees, as they are the only component of the beehive that carries out foraging activities and thus undergoes multiple interactions with both the environment and the hive.

The whole bees plus hive products system represents a very interesting and economical way to obtain samples that are useful for assessing contamination levels and their effects at the same time. Beehives are inexpensive and do not require a power supply, so they can be placed at any location. Beekeeping has been practiced worldwide since ancient times, and specialized personnel are not required to carry out biomonitoring using bees, except for those who are needed to perform and interpret analytical procedures (Van der Steen 2016). Given that the production of $1 \mathrm{~kg}$ of honey requires more than 100,000 foraging flights, 
it is clear that both honeybees and honey are appropriate random samples, so results obtained from honeybeebased monitoring will be highly representative of the average levels of accessible pollutants in the monitored area. Finally, honeybees are indispensable pollinators that are of great importance to ecosystem integrity. As they are bioindicators, honeybees can be used to assess and monitor changes in agricultural ecosystem quality and can supply ecological data (Quigley et al. 2019).

\section{The monitoring protocol}

Effective environmental biomonitoring requires programs that provide specific links between changes in environmental conditions and ecosystem health. Biomonitoring can be carried out using honeybees at different levels of complexity and sensitivity. The financial cost and the skills needed to perform such biomonitoring increase with the frequency of sampling, the diversity of the samples collected, and the amount of equipment and number of analytical techniques employed, but increasing any of these factors will also result in more data of greater quality. On the other hand, increasing these factors will reduce the field of applicability for biomonitoring. Thus, the appropriate level for each of the factors depends on the context and the aims of the biomonitoring performed.

A honeybees-hives system can be employed to passively sample and concentrate pollutants in order to obtain data on environmental quality in three main steps: field sampling by the bees; subsampling of dead or alive bees and hive products; and analytical determination of the contaminants followed by data processing (Van der Steen 2016).

The simplest experimental design involves placing a certain number of hives inside the region of interest, while another group - used as a control-is placed in a completely or relatively unpolluted area. Nevertheless, monitoring environmental pollution using honeybees requires the application of statistical tools to determine the optimal experimental design, starting with the sampling networks and the sampling procedures (Pirk et al. 2013; Dietemann et al. 2016). The number of stations and the number of samples collected per station must be planned in advance based on the characteristics of the sampled area, the presence and distribution of pollution sources, and atmospheric conditions. Moreover, the size and the type of the samples (dead or alive bees, hive products) to be collected and analyzed are selected beforehand based on statistical considerations: a sufficient number of samples must be taken to achieve the required statistical precision. The sample treatments and analytical techniques applied influence the number of samples that can be analyzed. Statistical tools must be used to process the large amount of data obtained, including sample measurements, atmospheric, agricultural, botanical, and geochemical information, and other useful data. Beyond the application of statistical tools to determine the significance of differences between the control area and the area suspected to be contaminated, ANOVA or paired $t$ tests (for example) can be applied to parametric data, or a MANOVA test to multianalyte data (Warne 2014). In fact, most of the analytical techniques used in honeybee-based biomonitoring are multielemental, so multivariate chemometric procedures such as principal component analysis or hierarchical cluster analysis are required to discern the relationships between various environmental variables and the contents of the samples (Yücel and Sultanoğlu 2012). Statistical methods can also be used to determine spatiotemporal variations in pollutant levels (Zaric et al. 2018).

Either dead or alive honeybees can be employed as the sampling population. In the former case, they are collected via cages, traps, underbaskets, etc. (Porrini et al. 2002), and the vegetation and areas visited by the bees are identified through pollen identification analysis. In nonsacrificial sampling of alive bees, the residues attached to their bodies are removed and collected on plastic surfaces on which the bees are forced to walk (Van der Steen 2016). Hive product sampling is always much easier. The best substrate to analyze depends on the kinds of analytes that are being investigated. Finally, the most appropriate sample treatment and analytical method will be employed to determine the chemicals encountered by the bees in their environment.

An alternative way of using honeybees to evaluate environmental quality is to look for changes in their behavior. It is possible to record the sound patterns at the hive, to monitor in-and-out movements of foraging bees, or to determine the number of bees using an infrared-based imaging system (Pérez et al. 2016; Chen et al. 2012; Shaw et al. 2011; Cousin et al. 2019). Laser-based optical systems that record the wing-beat frequency can be used to detect honeybee movements near the beehive or near a specific target, as well as those flying in the environment (Hoffman et al. 2007; Brydegaard et al. 2016). As an example, Table 2 reports the monitoring protocols we have applied in most of our studies.

\section{Current applications of biomonitoring using honeybees}

Historically, honeybees and hive products were initially used to monitor contamination from heavy metals and radionuclides (Svoboda 1961, 1962), which show high similarity in terms of their chemical properties and dynamics in the biosphere. These contaminants are still monitored by analyzing bees and their products (Badiou-Beneteau et al. 2013; Nikolić et al. 2016; Gutiérrez et al. 2015; Skorbilowicz et al. 2018). Later, honeybees were most commonly used to 
Table 2 Monitoring protocols utilized to monitor different contaminants in our studies

\begin{tabular}{|c|c|c|c|c|}
\hline Pollutant & $\begin{array}{l}\text { No. } \\
\text { hives/ } \\
\text { station }\end{array}$ & Analytical matrix & Analytical methods employed & Supplementary data \\
\hline Pesticides & 2 & Dead bees collected weekly from underbasket & SPME, GC, HPLC & $\begin{array}{l}\text { Mortality threshold: } \\
250 \text { bees/week/ } \\
\text { station } \\
\text { Crop-growing maps } \\
\text { Pollen identification }\end{array}$ \\
\hline Heavy metals & 2 & $\begin{array}{l}\text { Foraging bees captured every } 15 \text { days, and } \\
\text { fresh honey collected monthly }\end{array}$ & Mineralization, atomic ionization Spectroscopy & $\begin{array}{l}\text { Crop-growing maps } \\
\text { Pollen identification }\end{array}$ \\
\hline Radionuclides & 2 & Dead bees collected weekly from underbasket & Germanium crystal gamma spectrometry & $\begin{array}{l}\text { Crop-growing maps } \\
\text { Pollen identification }\end{array}$ \\
\hline
\end{tabular}

monitor the levels of pesticides in fields and on vegetables visited by honeybees (Quigley et al. 2019; Codling et al. 2016; Kasiotis et al. 2014; Barganska et al. 2018; de Oliveira et al. 2016). Several persistent organic pollutants (including explosive residues) originating from industrial and urban activities have also been isolated from bee samples and evaluated (Garcia-Valcarcel et al. 2016; Drummond et al. 2017; Simic et al. 2019; Gómez-Ramos et al. 2019). More recently, nanomaterials and nanoparticles have been added to the list of contaminants that honeybees can be used to monitor in the environment (Milivojevic et al. 2015; Kojic et al. 2020; Hooven et al. 2019; Glavan et al. 2017).

Since the beginning of the 1980s, our research group has been studying the best protocols for exploiting honeybees as bioindicators of environmental pollution, including pesticides, heavy metals, radionuclides, and phytopathogenic bacteria. The information supplied by palynological analysis and crop-growing maps was processed together with the chemical data in order to develop a predictive model suitable for environmental impact assessment (Porrini et al. 2002; Gentilomi et al. 2003).

\section{Heavy metals and elements}

Unfortunately, there is no area of the Earth that is completely free from contamination with heavy metals (HMs) of anthropogenic origin (Badiou-Beneteau et al. 2013). HMs are continually released from various natural and anthropic sources and are not degraded, so they become trapped in physical and biological cycles.

Since these pollutants have become ubiquitous, it is impossible to find uncontaminated control areas. Atmospheric metal deposition can occur over large areas far from the industrial and urban sources of those metals (Van der Steen et al. 2015; Van der Steen 2016). Monitoring studies can be employed to pinpoint new contamination sources or the origin and spread of a specific element.

Moreover, particular cunning must be used to avoid contamination from the materials employed to prepare the hive, or from the smoke used to calm bees, and finally from the containers used to collect, manipulate, or store the samples.

Regarding the choice of the most suitable matrix to analyze, most studies have studied dead bees and/or honey. In general, honeybees represent a better matrix for evaluating metal pollution than honey. Heavy metals in the atmosphere can be deposited on the hairy bodies of the bees and then brought into the hive with pollen, or they may be ingested with the nectar of flowers, water, or honeydew. A number of variables must be considered: the weather conditions, since rain and wind can clean the atmosphere; the nectar flow, which depends on the season; and the botanical origin of the honey, as aromatic plants concentrate pollutants and honey from deciduous trees has lower metal contents than honey from evergreen ones (Devillers et al. 2002; Yarsan et al. 2007). Thus, information obtained by palynological analysis on the botanical origin of honey can be fundamentally important. The soil composition can also affect the accumulation of metals in plants (Bogdanov et al. 2007).

By comparing atmospheric data with the results of bee analyses, it is possible to ascertain strong relationships between the abundances of metals in the environment and their levels on honeybees (Costa et al. 2019). Honeybees can provide additional information on heavy metal pollution, such as whether it is persistent or transitory. Various information is obtained by evaluating the data from samples obtained by washing the bees in acid (i.e., contaminants on the bees), data from samples containing only the metals ingested by the bees (obtained through wet acid digestion of the bees after washing their external surfaces), and data from samples containing the full body residues (obtained through simple mineralization of bees). As an example, during studies of the metal distributions in urban, industrial, and rural areas, we found that lead levels were higher inside the bees than on them $(p<0.0001)$ in urban and industrial areas, whereas the opposite was true in rural areas $(p<0.0005)$. For nickel, a significant difference between the levels found in and on the bees was only recorded in rural areas $(p<0.05)$, where levels were higher on the bees. Finally, significantly 
more chromium was found on than in the bees in all three environments (urban, $p<0.05$; industrial, $p<0.005$; rural, $p<0.005)$. The higher levels of all three metals on rather than in the bees in rural areas may suggest that these metals are scattered in the atmosphere and do not penetrate into or deposit on the environmental components visited by bees, so they do not tend to ingest them (Porrini et al. 2002).

Finally, it it is important to highlight the importance of using live bees to monitor metal contamination. Biomonitoring studies have shown that live bees are better for detecting high levels of heavy metals in the environment than dead ones (Ruschioni et al. 2013). Bees provide us with detailed information on recent changes in metal abundances, since the metals detected on them were collected during the previous 5 or 6 days (Porrini et al. 2002).

Honey and bee analyses can complement each other. A wide range of published papers have highlighted that honey is a suitable matrix for heavy metal detection (Herrero Latorre et al. 2018), but several studies have demonstrated that this matrix does not accurately reflect the environmental contamination level (Fakhimzadeh and Lodenius 2000; Conti and Botre 2001; Tuzen et al. 2007; Sadegh et al. 2012; Silici et al. 2013). The mineral content of honey has been found to be highly correlated with its geographical and botanical origins, its geochemical composition, and with local pollution levels. Thus, the composition of the honey can be considered to be indicative of a wide range of environmental factors (Sajtos et al. 2019; Fermo et al. 2013).

\section{Radionuclides}

Small amounts of radionuclides can be dispersed into the environment by the chimneys of nuclear power plants, by health establishments, in army simulations of a nuclear accident, or by inappropriate disposal of radioactive sources in foundries (Porrini et al. 2002). However, the largest contributions to radionuclide contamination come from nuclear experiments performed in the atmosphere (Svoboda 1962) and leakages from or accidents at nuclear power plants. Radioactive particles that are dispersed into the air will gradually be deposited on soil and vegetables. Some of these deposited radionuclides are subsequently picked up by visiting insects, or they can be transferred into agricultural products or grazing animals, ultimately to be ingested by humans. The high suitability of honeybees and hive products for collecting radioisotopes from the environment was unequivocally demonstrated by several studies performed immediately after the Chernobyl accident. Those studies used bees and hive products to understand the distribution of the radioactive fallout and the transfer dynamics. Our research group analyzed numerous samples of honey, bees, wax, and pollen. The results demonstrated that pollen was the best indicator of atmospheric contamination levels, and the bees themselves proved to be useful: measurements of the radionuclides in this matrix showed a strong correlation with ground deposition values $(R=0.95)$. On the other hand, the radioactivity of honey was found to be greatly influenced by its pollen content (Tonelli et al. 1990). Soil composition and botanical origin also influence the radionuclide concentration in honey. Nevertheless, most of the studies carried out in the last 25 years have chosen honey as the matrix to analyze, probably because honey samples are the easiest to collect and the analytical technique is extremely sensitive and selective (Assman Assman-Werthmüller et al. 1991; Barišić et al. 2002; Panatto et al. 2007; Borowska et al. 2013; Meli et al. 2016). In fact, it is very easy to check for the presence of radionuclides in any kind of matrix without the need for any sample pretreatment. The bee matrix can be used to rapidly check for the presence of radioactivity in the atmosphere, even at levels that are far below every alarm threshold, with higher efficiency than traditional monitoring techniques (Porrini et al. 2002).

\section{Pesticides}

These compounds are used extensively in agriculture. Newly developed families of pesticides are continuously spread on cultivated fields to control attacks from parasites that grow increasingly pesticide resistant. The side effects of these pesticides on untargeted organisms such as pollinators are nonnegligible.

Honeybees are extremely sensitive to pesticides. Bees capture insecticidal compounds mainly through the ingestion of water/liquids from a variety of sources, including ditches, puddles, canals, brooks, fountains, and dew. The hairs on their bodies intercept particles suspended in the atmosphere.

When captured, some compounds can be so toxic that the bees do not have enough strength to return to their hives; they die in the field or during their return flight. Bees that are only marginally damaged by a captured compound will eventually die in their hives. In this case, the honeybees act as direct indicators. The number of dead bees in front of the hive will vary according to the toxicity of the active principle (Atkins et al. 1981), the blooming of cultivated or spontaneous plants, the presence of honeybees during the chemical treatment, the means used to distribute the pesticide, the presence of wind, and other factors.

For compounds that are not particularly dangerous, the insect can act as an indirect indicator (i.e., it is not sensitive to the compound but it has been exposed to it), and can therefore provide us with information in the form of residues that we can analyze.

The identification of pollen in hive products or on the bees themselves, together with detailed knowledge of the vegetation present within the flying range of the bees, is 
Table 3 The various pesticides revealed by GC and the number of positive samples among those collected during the period from April to October from three monitoring stations in rural Bologna (n 1= Ozzano Emilia, n 2= Granarolo Emilia, n $3=$ Bologna), selected at random

\begin{tabular}{|c|c|c|c|}
\hline Pesticide & Station n 1 & Station n 2 & Station n 3 \\
\hline \multicolumn{4}{|c|}{ Number of contaminated samples } \\
\hline Malathion & 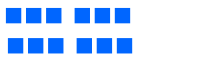 & 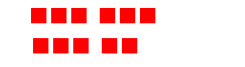 & 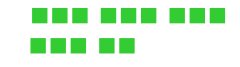 \\
\hline Dimethoate & 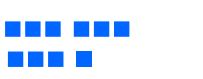 & 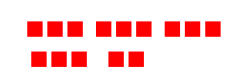 & 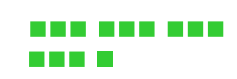 \\
\hline Methyl-parathion & घ日 m & 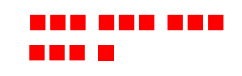 & man \\
\hline Parathion & घ日 & घn & $\mathbf{\square}$ \\
\hline Omethoate & $\mathbf{m} \mathbf{n}$ & $\mathbf{m} \mathbf{m} \mathbf{m}$ & घ \\
\hline Pirimicarb & $\mathbf{m} \square \mathbf{m}$ & $\mathbf{\square}$ & \\
\hline Methidathion & - & - & $\mathbf{m}$ \\
\hline Chlorpyrifos & $\mathbf{\square}$ & & $\mathbf{\square}$ \\
\hline Coumaphos & - & & - \\
\hline Phosphamidon & & - & घ \\
\hline Paraoxon & & $\mathbf{\square}$ & \\
\hline Pirimiphos-methyl & & $\square$ & \\
\hline Quinalphos & & $\mathbf{\square}$ & \\
\hline Azinphos-methyl & & $\mathbf{\square}$ & \\
\hline Bromophos & & - & \\
\hline Heptenophos & & - & \\
\hline Phenthoate & & घ & \\
\hline
\end{tabular}

of fundamental importance when attempting to identify the crops visited and treated.

During our monitoring activities, which were performed using only dead bees, we were able to obtain data on weekly mortality, a list of active ingredients that were responsible for the bee deaths (Table 3), and-by processing the complete data set-monthly maps showing the degree of contamination of the monitored territory. On these maps, each area visited by bees around each station was assigned to one of fourteen pollution categories of the index of environmental hazard (IEH). These categories were fixed based on a combination of bee mortality and the index of pesticide toxicity (IPT), which depends on both the toxicity and the persistence of the pesticide (Fig. 2). Poor plant protection management, such as performing treatments on windy days or when the crops are flowering, were also easily identified (Ghini et al. 2004, Girotti et al. 2013).

\section{Phytopathogenic microorganisms}

Phytopathogenic bacteria are a particular type of contaminant. Erwinia amylovora (Burrill 1882) Winslow et al. 1920 is the causal agent of fire blight, the most destructive bacterial disease of rosaceous plants (Van der Zwet 1996). This serious disease is able to spread rapidly over large areas, destroying crops of great economic importance (pear and apple orchards) and ornamental and natural species such as hawthorn. Currently, the only way to fight against this destructive plant disease is to stop it from spreading by identifying the presence of the bacteria early and then eliminating the affected plants (Van der Zwet and Beer 1995). Honeybees were found to be a potential short-range vector of the disease during their foraging activities. On the other hand, their ability to intercept the bacterium makes bees a powerful indicator of the presence of this pathogen in their flight range. Monitoring for the presence of a small but significant amount of pathogenic bacteria on bees could allow the disease to be detected before visual field inspections observe its symptoms (Sabatini et al. 2006).

In our experience of monitoring for E. amilovora, it immediately became obvious that analytical methods that are more sensitive and specific than standard microbiological techniques would be need to be used in conjunction with honeybee-based sampling. A molecular techniquepolymerase chain reaction (PCR) — was therefore employed to improve the specificity and detection limit of the assay. The few copies of E. amilovora DNA found in the samples were amplified using this technique and then separated on 

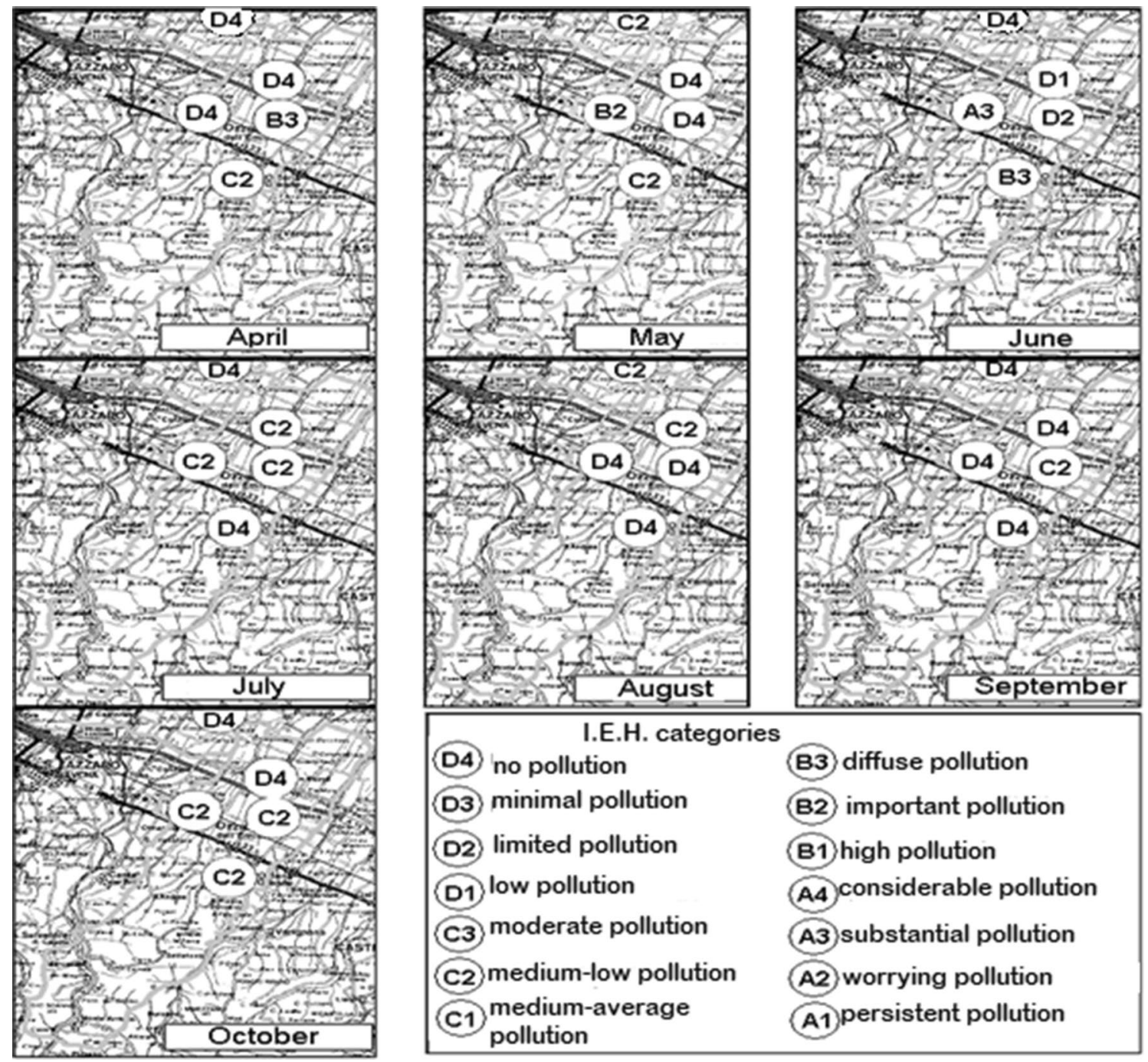

\begin{tabular}{|c|c|}
\hline \multicolumn{2}{|c|}{ I.E.H. categories } \\
\hline (D4) no pollution & B3) diffuse pollution \\
\hline (D3) minimal pollution & B2 important pollution \\
\hline (D2) limited pollution & (B1) high pollution \\
\hline D1 low pollution & (A4) considerable pollution \\
\hline (C3) moderate pollution & A3 substantial pollution \\
\hline (C2) medium-low pollution & A2 worrying pollution \\
\hline (C1) medium-average & A1 persistent pollution \\
\hline
\end{tabular}

Fig. 2 Examples of monthly maps of pesticide contamination in a territory around Bologna (Italy) that includes five monitoring stations. Each station was assigned monthly to an index of environmental hazard (IEH) category. The IEH is an indicator of environmental risk, since it is a combination of the honeybee mortality class (monthly

96-well microplates via bonding with a specific DNA oligo probe. Detection was achieved using an immunoenzymatic enhanced chemiluminescent assay performed directly on the microplates (ECL-PCR-ELISA) (Merighi et al. 2000). The aim was to obtain an early warning system that can reveal the presence of this pathogen at trace levels in rosaceous pollen samples collected in seemingly uncontaminated areas, thus allowing sufficient time for intervention before the pathogen causes visible damage.

The samples analyzed were pollen and forager honeybees leaving the hive, with the pollen preferred due to ease of sampling. Palynologic analysis revealed that rosaceous plants were among those visited by the honeybees. mean of dead bees/week) and the index of pesticide toxicity (IPT), which is calculated taking into account the toxicity and the persistence of the pesticide (or a mean IPT value when multiple pesticides are present) (Porrini et al. 2002)

The monitoring stations are ideally distributed in circles centered on the infected areas. Alternatively, they can be aligned perpendicular to the disease expansion front. For example, we employed the latter approach, starting from the edge of the infected zone and separating the stations by $4 \mathrm{~km}$ up to $26 \mathrm{~km}$ from the edge. All of the areas monitored were considered to be unaffected based on visual inspections of plants, but our analysis of samples from several of the monitoring stations indicated the presence of E. amilovora in at least one sample/station. Due to the distance of the pathogen-positive monitoring station from the infected area, it took 4 months for visible symptoms of fire blight to appear on host plants close to that station, and more than a year for 
host plants near to a station about $22 \mathrm{~km}$ from the original disease front to show signs of the disease.

\section{Explosives, nanoparticles, and other organic pollutants}

Trace sensing of explosive vapor is a method that is used to detect mines and improvised explosive devices (IEDs). However, trace sampling in the field can be extremely difficult due to various factors, including the very low vapor pressures of the explosives of interest. It may be too risky to allow humans or dogs access to areas suspected of harboring mines. Honeybees can safely survey areas contaminated with landmines by collecting explosive materials on their body hairs, which electrostatically attract tiny particles of explosives suspended in the air. After the bees have returned to their hive, the particles and explosive molecules present on their bodies can be collected and concentrated.

The more or less successful detection of trace levels of explosives has also been achieved using another strategy: sniffer bee technology (Rodacy et al. 2002; Hadagali and Suan 2017), which involves training thousands of bees to seek the specific odors of 2-4-dinitrotoluene and TNT (Bromenshenk et al. 2003a, b; Anderson et al. 1999; Macias 2009). Honeybees have the ability to distinguish between than 170 odors; this ability is crucial to their ability to seek out nectar, pollen, water, tree resin, and pheromones (Halter 2011). In this case, honeybees are not employed for biomonitoring but as highly sensitive, accurate, and cost-effective biosensors. This sniffer bee approach has been applied in various fields, such as theaters of war, during customs inspections to detect narcotics (Keith and Rooth 2012) and cigarettes (Wells and Bradley 2012), to support forensic investigations (Frederickx et al. 2011), and to discern food adulteration (Bonod et al. 2003).

As mentioned before, by determining the residues recovered from bees and hive product samples, it is possible to characterize the complete organic pollution patterns of the samples in just one analysis. Phthalates and PAHs (GómezRamos et al. 2019), polychlorinated biphenyls (Bargańska and Namieśnik 2010), azoles and organophosphorus esters (Garcia-Valcarcel et al. 2016), and a wide spectrum of other persistent organic pollutants (Wei et al. 2016) have been determined simultaneously in bees and hive products extracts. A comprehensive list of the pollutants present in the environment is necessary to correctly ascribe the assessed biotoxicity to its causative compounds.

Finally, the enormous proliferation of nanomaterials and their applications has led to these particles being placed on the list of environmental pollutants. Their spread across urban and rural areas has already put them into contact with honeybees. The toxic, or sometimes even beneficial, characteristics of nanomaterials such as $\mathrm{ZnO}$, fullerenol, nanotechnology-based pesticides, and silver nanoparticles coupled to plant extracts have been investigated (Milivojevic et al. 2015; Kojic et al. 2020; Hooven et al. 2019). The present studies were based on the particular adaptation of the pollinator to collect pollen, and then on the assumption that any other types of environmental particles can also be actively gathered by bees.

\section{Sample treatment and analysis}

Honeybees, frozen or lyophilized after collection, are the most complex matrix to treat and to analyze. Pollen, propolis, and wax are simply stored in containers at room temperature under fresh and dry conditions. Honey and honeydew are stored in glass containers at $4{ }^{\circ} \mathrm{C}$ in the dark. Sample treatments and analytical techniques vary according to the analyte of interest.

\section{Elements and heavy metals}

Metal determination is achieved using various atomic spectrometry techniques. Biological samples such as bees or honey must be mineralized before analysis. When studying bees, it is possible to analyze the metals deposited on the body separately from those ingested (together with nectar, water, and other liquids) by the bee. The metals on the bees can be collected by washing them with a $5 \%$ solution of acid $\left(\mathrm{HNO}_{3}\right)$, whereas the ingested metals can be extracted by exposing the previously washed bees to wet acid digestion using various acids $\left(\mathrm{HCl}, \mathrm{HNO}_{3}\right.$, and $\left.\mathrm{H}_{2} \mathrm{O}_{2}\right)$ with or without microwave irradiation (Porrini et al. 2002; Lambert et al. 2012; Van der Steen et al. 2012; Silici et al. 2013; Gutiérrez et al. 2015). Honey can be mineralized or simply diluted, for example $1: 20$, in a $0.2 \%$ Triton X-100 water solution (Porrini et al. 2002).

A number of analytical techniques can be used to determine the levels of various metals, but the most popular (and suitable) are those based on atomic spectrometry (Pohl et al. 2012; Herrero Latorre et al. 2018). One of the most powerful of these is atomic absorption spectrometry, operated in either flame or electrochemical atomic absorption (EAA) mode. Electrothermal atomizers are advantageous in that they facilitate low limits of detection and require only very small sample volumes, which is useful when analyzing biological samples. When the metal concentrations are relatively high, flame atomic absorption can be sufficiently sensitive. Other techniques such as ICP-OES (inductively coupled plasma spectrometry-optical emission spectrometry) and ICP-MS (inductively coupled plasma spectrometry-mass spectrometry) offer the possibility of performing multielemental analysis in a single step. ICP-MS is the technique of choice when a high sensitivity is needed (Herrero 
Latorre et al. 2018). A microwave plasma atomic emission spectroscopy (MP-AES) technique for the elemental analysis of honey samples has also been validated (Sajtos et al. 2019).

\section{Radionuclides}

The qualitative and quantitative determination of radionuclides is always performed without any sample pretreatment due to the nature and high selectivity of the analytical technique applied. Each gamma-emitting radionuclide has a characteristic spectral intensity and energy, which makes gamma-ray spectrometry (GRS) using a low background hyper-pure germanium semiconductor detector and a multichannel analyzer an extremely selective and sensitive technique. Even very low levels of radioactivity can be detected, including the background emission from natural radionuclides, and comparisons of data from different laboratories are possible (Gilmore 2008; Meli et al. 2016).

\section{Pesticides and organic pollutants}

Analyzing these kinds of contaminants requires their careful and complete separation from highly complex organic matrices (i.e., bee bodies or hive products). Moreover, these matrices do not contain just one contaminant, but a mixture of chemically different residues, which are ideally separated and determined at the same time in a single assay.

After separating the residues from the selected matrix, it can be useful or necessary to carry out clean-up procedures, since bee or bee product extracts usually contain interferents such as fats, pigments, and carbohydrates. In some cases, analysis of the analyte will require a concentration step to ensure that the analyte level is above the detection limit of the analytical method used.

The extraction and purification procedures applied depend on the composition of the matrix examined-either pollen, beebread, honey, wax, propolis, royal jelly, or the whole bee (Rossi et al. 2001; Fernandéz et al. 2001, 2002; Ghini et al. 2004). Gel permeation chromatography (GPC), liquid-liquid extraction (LLE), solid-phase (micro)extraction (SP(M)E), matrix solid phase dispersion (MSPD), supercritical fluid extraction (SFE), and ultrasonic extraction (UE) are the most commonly used techniques (Bargańska and Namieśnik 2010). Extract clean-up is often performed using separation columns filled with materials such as XAD4, Florisil, C18, or graphite soot, by filtering the extract through Celite layers, and/or by adding coagulating solutions such as an ammonium chloride and orthophosphoric acid mixture. All of the analytical methods employed are multiresidual, and a QUEChERS technique is highly recommended for organic pollutants extracted from organic matrices, including pesticides.
Given that the extracts contain a large number of organic compounds with a wide range of chemical characteristics, both liquid chromatography (LC) and gas chromatography (GC) are employed to analyze them. LC is generally applied to examine thermolabile, polar, and lowvolatility compounds, whereas GC can be used to determine thermostable and/or volatile compounds. Both of these chromatographic approaches are frequently coupled to mass spectrometry (MS), tandem mass spectrometry (MS/MS), or high-resolution mass spectrometry (HRMS) in order to achieve the maximum detection sensitivity (Kasiotis et al. 2014, 2018; Bargańska and Namieśnik 2010; Gómez-Ramos et al. 2019; Tong et al. 2018; Niell et al. 2017). However, other detection techniques can be employed for pesticide analysis. For example, we identified compounds that had been separated by GC using nonselective detectors such as nitrogen phosphorus (NPD), flame ionization (FID), and electron capture (ECD) detectors (Rossi et al. 2001). We also coupled an UV detector, or-after a postcolumn photochemical derivatization stage-a fluorescence detector to a HPLC instrument (Gil García et al. 2007).

LC-based separation can be coupled to mass spectrometry detection by various interfaces, such as electrospray ionization (ESI) (Kasiotis et al. 2018) or atmospheric pressure chemical ionization (APCI) - a soft ionization technique that yields quasimolecular ions and results in high detection sensitivity and information on molecular weight (Totti et al. 2006). GC is often coupled to mass spectrometry by a "hard" electron ionization (EI) interface.

The number of organic contaminants (not only pesticides) in the environment continues to rise each day, and new sample treatments (e.g., QuEChERS) are able to extract all of them, including unknown or untargeted pollutants such as metabolites of the targeted pollutants (Cotton et al. 2014; Kasiotis et al. 2018; Gómez-Ramos et al. 2016, 2019). Mass spectrometers operating in multiple reaction monitoring (MRM) mode cannot detect all of these compounds, so researchers prefer to use HRMS detection, which is performed in a full-scan mode such as time-of-flight (TOF), Fourier transform ion cyclotron resonance (FT-ICR), or Orbitrap analysis. These multiresidual methods make it possible to detect the presence of compounds that are banned or unauthorized for use in the region of interest, which might otherwise never be investigated (Malhat et al. 2015; Perugini et al. 2018).

Enzyme and monoclonal antibody-based immunoassays are also being developed. These methods strongly contrast with those described above, as they are very specific, sensitive, and rapid techniques for determining the presence of a specific target compound in a complex mixture of chemicals. Introducing chemiluminescent end-point detection into an immunoassay can greatly improve its detection limit. These 
assays have been successfully used to detect a compound present at trace levels (Botchkareva et al. 2003; Mickova et al. 2005; Ivanov et al. 2008; Girotti et al. 2008, 2010; Soler et al. 2008).

Recently, Gillanders et al. (2019) developed a special detection method for explosive residues. The main hurdle to explosive detection is obtaining a sufficient amount of analyst for analysis, so the Authors placed strips containing a commercial fluoropolymer (AFLAS) in the entrances to the beehives. Explosive molecules collected by honeybees while flying are collected, absorbed, and concentrated by the strips as the bees enter their hives. Subsequent detection of the explosive occurs via the luminescence quenching response from the organic polymer Super Yellow (Gillanders et al. 2019).

\section{Conclusions}

Environmental pollution is one of the main issues that must be addressed by contemporary society, and the global nature of this problem implies that methods of monitoring the quality of the environment should be suitable for application in regions with completely different environmental, infrastructural, social, and economic conditions.

Biomonitoring utilizes organisms that are sensitive, ubiquitous, and stable in the territory of interest to obtain accurate information on the pollutants present in the territory as well as their biotoxic effects. Honeybees have been shown to satisfy all these requirements.

Wild and domestically raised honeybees are widespread in the Mediterranean area. The chance to collect and compare homogeneous data obtained from large territories using the same sampling technique makes it possible to derive unexpected and very useful information for the integrated management of environmental aspects at scales larger than individual countries. Moreover, data obtained by analyzing bees and their products can help beekeepers to preserve bee populations by avoiding heavily contaminated areas. Such data can also be useful when attempting to establish environmental limits on the concentrations of contaminants that are toxic to humans or bees (Sgolastra et al. 2020).

Finally, one of the key aspects of sustainable development is the active participation of citizens in actions to tackle environmental issues. This is particularly true of young people, for whom we must conceive and develop appropriate educational programs. Committed as we are to helping to educate the public in environmental issues, we have prepared an online openaccess course in multiple languages (Italian, Spanish, and English) as a means to pass on our knowledge of the application of honeybees in environmental protection activities (http://openl earning.unibo.it/?lang=en).
Author contributions All of the authors contributed equally.

Funding Open access funding provided by Alma Mater Studiorum Università di Bologna within the CRUI-CARE Agreement. This work was supported by grants (RFO 2018 and 2019) from the University of Bologna.

Availability of data and material Data and material are available from the Department of Pharmacy and Biotechnology, University of Bologna.

\section{Compliance with ethical standards}

Conflicts of interest All author(s) declare that they have no conflict of interest.

Open Access This article is licensed under a Creative Commons Attribution 4.0 International License, which permits use, sharing, adaptation, distribution and reproduction in any medium or format, as long as you give appropriate credit to the original author(s) and the source, provide a link to the Creative Commons licence, and indicate if changes were made. The images or other third party material in this article are included in the article's Creative Commons licence, unless indicated otherwise in a credit line to the material. If material is not included in the article's Creative Commons licence and your intended use is not permitted by statutory regulation or exceeds the permitted use, you will need to obtain permission directly from the copyright holder. To view a copy of this licence, visit http://creativecommons.org/licenses/by/4.0/.

\section{References}

Al-Alam J, Chbani A, Faljoun Z, Millet M (2019) The use of vegetation, bees, and snails as important tools for the biomonitoring of atmospheric pollution-a review. Environ Sci Poll Res 26:9391-9408

Anderson G, Prior D, Gilbert R (1999) RF tagging of insects: honeybees for land-mine detection. In: Computing and information sciences. Annual report no. PNNL-13184. William R. Wiley Environmental Molecular Sciences Laboratory, Richland

Asif N, Malik MF, Chaudry FN (2018) A review of on environmental pollution bioindicators. Pollution 4:111-118

Assman-Werthmüller U, Werthmüller K, Molzahn D (1991) Cesium contamination of heather honey. J Radioanal Nucl Chem 149:123-129

Atkins EL, Kellum D, Atkins KW (1981) Reducing pesticides hazards to honey bees: mortality prediction techniques and integrated management strategies. Univ Calif Div Agric Sci Leaf 2883:1-23

Badiou-Beneteau A, Benneveau A, Geret F et al (2013) Honeybee biomarkers as promising tools to monitor environmental quality. Environ Int 60:31-41

Bargańska Z, Namieśnik J (2010) Pesticide analysis of bee and bee product samples. Crit Rev Anal Chem 40:159-171

Bargańska Z, Konieczka P, Namieśnik J (2018) Comparison of two methods for the determination of selected pesticides in honey and honeybee samples. Molecules 23(10):2582. https://doi. org/10.3390/molecules23102582

Barišić D, Bromenshenk JJ, Kezić N, Vertačnik A (2002) The role of honeybees in environmental monitoring in Croatia. In: Devillers J, Pham-Delègue MH (eds) Honey bees: estimating the environmental impact of chemicals. Routledge-Taylor \& Francis Group, London, pp 160-185 
Batzias F, Siontorou CG (2007) A novel system for environmental monitoring through a cooperative/synergistic scheme between bioindicators and biosensors. J Environ Manag 82:221-239

Bogdanov S, Haldimann M, Luginbuhl W, Gallman P (2007) Minerals in honey: environmental, geographical and botanical aspects. J Apicult Res 46:269-275

Bonod I, Sandoz JC, Loublier Y, Delegue MHP (2003) Learning and discrimination of honey odours by the honey bee. Apidol 34:147-159

Borowska MH, Kapala J, Puścion-Jakubik A, Horembala J (2013) Radioactivity of honeys from Poland after the Fukushima accident. B Environ Contam Tox 91:489-492

Botchkareva AE, Eremin SA, Montoya A et al (2003) Development of chemiluminescent ELISA to DDT and its metabolites in food and environmental samples. J Immunol Meth 283:45-57

Bromenshenk JJ, Henderson CB, Seccomb RA, et al (2003a) Can honeybees assist in area reduction and landmine detection? J Mine Action 7:3

Bromenshenk JJ, Henderson CB, Smith GC (2003b) MR-1608. In: McDonald J, Lockwood JR, Mcfee J, Altshuler T, Broach T, Carin LC, Rappaport WR, Scott RW (eds) Alternatives for landmine detection. RAND Science and Technology Policy Institute, Washington, DC, pp 273-283 (Appendix S)

Brydegaard M, Merdasa A, Gebru A, Jayaweera H (2016) Realistic instrumentation platform for active and passive optical remote sensing. Appl Spectrosc 70:372-385

Butterworth FM, Corkum LD, Guzmán-Rincón J (1995) Biomonitors and biomarkers as indicators of environmental change. Environmental science research, vol 50. Plenum, London

Chen C, Yang E-C, Jiang J-A, Lin TT (2012) An imaging system for monitoring the in-and-out activity of honey bees. Comput Electron Agricult 89:100-109

Codling G, Al Naggar Y, Giesy JP, Robertson AJ (2016) Concentrations of neonicotinoid insecticides in honey, pollen and honey bees (Apis mellifera L.) in central Saskatchewan, Canada. Chemosphere 144:2321-2328

Conti ME, Botre F (2001) Honeybees and their products as potential bioindicators of heavy metal contamination. Environ Monit Assess 69:267-282

Costa A, Veca M, Barberis M et al (2019) Heavy metals on honeybees indicate their concentration in the atmosphere: a proof of concept. Italian J Animal Sci 18:309-315

Cotton J, Leroux F, Broudin S et al (2014) High-resolution mass spectrometry associated with data mining tools for the detection of pollutants and chemical characterization of honey samples. $\mathbf{J}$ Agric Food Chem 62:11335-11345

Cousin P, Căuia E, Siceanu A, de Cledat J (2019) The development of an efficient system to monitor the honeybee colonies depopulations. In: 2019 Global IoT Summit (GIoTS), Aarhus, Denmark, 17-21 June 2019, pp 1-5. https://ieeexplore.ieee.org/docum ent/8766435. Accessed 30 Mar 2020

de Oliveira RC, do Nascimento Queiroz SC, Pinto da Luz CF et al (2016) Bee pollen as a bioindicator of environmental pesticide contamination. Chemosphere 163:525-534

Devillers J, Pham-Delegue MH (2002) Honey bees: estimating the environmental impact of chemicals. Taylor and Francis, London

Devillers J, Doré JC, Marenco M et al (2002) Chemometrical analysis of 18 metallic and non metallic elements found in honeys sold in France. J Agric Food Chem 5:5998-6007

Dietemann V, Ellis JD, Neumann P (eds) (2016) COLOSS BeeBook volume I: standard methods for Apis mellifera research. Institute of Bee Health, University of Bern, Bern

Dolores Hernando M, Gamiz V, Gil-Lebrero S, Rodriguez I et al (2018) Viability of honeybee colonies exposed to sunflowers grown from seeds treated with the neonicotinoids thiamethoxam and clothianidin. Chemosphere 202:609-617
Drummond J, Williamson SM, Fitchett AE, Wright GA, Judge SJ (2017) Spontaneous honeybee behaviour is altered by persistent organic pollutants. Ecotoxicology 26:141-150

El-Saad AMA, Kheirallah DA, El-Samad LM (2017) Biochemical and histological biomarkers in the midgut of Apis mellifera from polluted environment at Beheira Governorate, Egypt. Environ Sci Pollut Res 2:3181-3193. https://doi.org/10.1007/s1135 6-016-8059-1

EU (2000) The Water Framework Directive (WFD) 2000/60/EC. Off J EU 327:1-73

EU (2008) Ambient air quality and clearer air for Europe Directive 2008/50/EC. Off J EU 152:1-73

EU (2008) Integrated Pollution Prevention and Control (IPPC) Directive 2008/1/EC. Off J EU 24:8-29

EU (2010) Directive 2010/75/EC on industrial emissions (integrated pollution prevention and control). Off J EU 134:17-119

EU (2015) Commission Implementing Decision 2015/495 of 20 March 2015 establishing a watch list of substances for Union-wide monitoring in the field of water policy pursuant to Directive 2008/105/EC of the European Parliament and of the Council. Off J EU 78:40-42

EU (2018) Commission Implementing Decision 2018/840 of 5 June 2018 establishing a watch list of substances for Union-wide monitoring in the field of water policy pursuant to Directive 2008/105/EC of the European Parliament and of the Council and repealing Commission Implementing Decision (EU) 2015/495. Off J EU 141:9-12

Fakhimzadeh K, Lodenius M (2000) Honey, pollen and bees as indicator of metal pollution. Acta U Carol Environ 14:13-20

Fermo P, Beretta G, Facinio RM, Gelmini F, Piazzalunga A (2013) Ionic profile of honey as potential indicator of botanical origin and global environmental pollution. Environ Pollut 178:173-181

Fernandéz M, Padron C, Marconi L et al (2001) Determination of organophosphorous pesticides in honeybees after solid-phase microextraction. J Chromat A 922:257-265

Fernandéz M, Picó Y, Mañes J (2002) Analytical methods for pesticide residues determination in bee products. J Food Protect 65:1502-1511

Frederickx C, Verheggen FJ, Haubrughe E (2011) Biosensors in forensic science. Biotechnol Agron Soc Environ 15:449-458

Garcia-Valcarcel AI, Molero E, Tadeo JL, Hernando MD (2016) Determination of selected environmental contaminants in foraging honeybees. Talanta 148:1-6

Gentilomi G, Zeri L, Ghini S, Zerbini M et al (2003) Expression of firefly luciferase gene in Erwinia amylovora: a sensitive gene marker to follow bacterial infection and dissemination. Luminescence 18:207-213

Ghini S, Fernandez M, Picó Y et al (2004) Occurrence and distribution of pesticides in the province of Bologna, Italy, using honeybees as bioindicators. Arch Environ Contam Toxicol 47:479-488

Gil García MD, Martínez Galera M, Santiago Valverde R, Galanti A, Girotti S (2007) Column switching liquid chromatography and post-column photochemically fluorescence detection to determine imidacloprid and 6-chloronicotinic acid in honeybees. J Chromat A 1147:17-23

Gillanders RN, Glackin JME, Filipi J et al (2019) Preconcentration techniques for trace explosive sensing. Sci Total Environ 658:650-658

Gilmore GR (2008) Practical gamma-ray spectrometry. Wiley, Chichester

Girotti S, Maiolini E, Ghini S et al (2008) Quantification of Thiram in honeybees: development of a chemiluminescent ELISA. Anal Lett 41:46-55 
Girotti S, Maiolini E, Ghini S, Eremin SA, Mañes J (2010) Quantification of Imidacloprid in honeybees: development of a chemiluminescent ELISA. Anal Lett 43:466-475

Girotti S, Ghini S, Maiolini E, Bolelli L, Ferri EN (2013) Trace analysis of pollutants by use of honeybees, immunoassays, and chemiluminescence detection. Anal Bioanal Chem 405:555-571

Glavan G, Milivojevic T, Bozic J, et al (2017) Feeding preference and sub-chronic effects of $\mathrm{ZnO}$ nanomaterials in honey bees (Apis mellifera carnica). Arch Environ Contam Toxicol 72:471-480

Gómez-Ramos MM, García-Valcárcel AI, Tadeo JL, Fernández-Alba AR, Hernando MD (2016) Screening of environmental contaminants in honey bee wax comb using gas chromatography-highresolution time-of-flight mass spectrometry. Environ Sci Pollut Res 23:4609-4620

Gómez-Ramos MM, Ucles S, Ferrer C, Fernández-Alba AR, Hernando MD (2019) Exploration of environmental contaminants in honeybees using GC-TOF-MS and GC-Orbitrap-MS. Sci Total Environ 647:232-244

Gutiérrez M, Molero R, Gaju M, van der Steen J, Porrini C, Ruiz JA. (2015) Assessment of heavy metal pollution in Córdoba (Spain) by biomonitoring foraging honeybee. Environ Monit Assess 187:651-665

Hadagali MD, Suan CL (2017) Advancement of sensitive sniffer bee technology. TrAC Trends Anal Chem 97:153-158

Halter R (2011) The incomparable honeybee and the economics of pollination. Rocky Mountain Books, Calgary

Hernandez F, Bakker J, Bijlsma L et al (2019) The role of analytical chemistry in exposure science: focus on the aquatic environment. Chemosphere 222:564-583

Herrero Latorre C, Barciela García J, García Martín S, Peña-Crecente RM (2018) The use of honeybees and honey as environmental bioindicators for metals and radionuclides: a review. Environ Rev https://mc06.manuscriptcentral.com/er-pubs. Accessed 30 Mar 2020

Hoffman DS, Nehrir AR, Repasky KS, Shaw JA, Carlsten JL (2007) Range-resolved optical detection of honeybees by use of wingbeat modulation of scattered light for locating mines. Appl Opt 46:3007-3012

Hooven LA, Chakrabarti P, Harper BJ et al (2019) Potential risk to pollinators from nanotechnology-based pesticides. Molecules 24:4458. https://doi.org/10.3390/molecules24244458

Horne J, McLoughlin L, Bury E et al (2020) Interfacial phenomena of advanced composite materials toward wearable platforms for biological and environmental monitoring sensors, armor and soft robotics. Interfaces 7:1901851. https://onlinelibrary. wiley.com/doi/pdf/10.1002/admi.201901851

Ivanov A, Evtugyn G, Budnikov $\mathrm{H}$ et al (2008) Amperometric immunoassay of azinphos-methyl in water and honeybees based on indirect competitive ELISA. Anal Lett 41:392-405

Kasiotis KM, Anagnostopoulos C, Anastasiadou P, Machera K (2014) Pesticide residues in honeybees, honey and bee pollen by LC-MS/MS screening: reported death incidents in honeybees. Sci Total Environ 485-486:633-642

Kasiotis KM, Tzouganaki ZD, Machera K (2018) Chromatographic determination of monoterpenes and other acaricides in honeybees: prevalence and possible synergies. Sci Total Environ 625:96-105

Keith C, Rooth M (2012) Sniffer bees. Chemistry \& Industry, issue 9. http://www.soci.org/chemistry-andindustry/cni-data/2012/9/ sniffer-bees. Accessed 30 Mar 020

Kojic D, Purac J, Celic TV et al (2020) Effect of fullerenol nanoparticles on oxidative stress induced by paraquat in honey bees. Environ Sci Pollut Res 27:6603-6612

Lai FY, Rauert C, Gobelius L et al (2019) A critical review on passive sampling in air and water for per- and polyfluoroalkyl substances (PFASs). TrAC Trends Anal Chem 121:115311. https://doi.org/10.1016/j.trac.2018.11.009

Lambert O, Piroux M, Puyo S et al (2012) Bees, honey and pollen as sentinels for lead environmental contamination. Environ Pollut 170:254-259

Li X, Wang L, Du D et al (2019) Emerging applications of nanozymes in environmental analysis: opportunities and trends. Trends Anal Chem 120:115653

Ma J, Li Z, Cheng JCP et al (2020) Air quality prediction at new stations using spatially transferred bidirectional long shortterm network. Sci Total Environ 705:135771. https://doi. org/10.1016/j.scitotenv.2019.135771

Macias SM (2009) The development of an optimized system of narcotic and explosive contraband mimics for calibration and training of biological detectors. Dissertation. http://digitalcom mons.fiu.edu/etd/123. Accessed 30 Mar 2020

Mahapatra B, Dahl NK, Dash AK et al (2019) Perspective of mitigating atmospheric heavy metal pollution using mosses as biomonitoring and indicator organism. Environ Sci Pollut 26:29620-29638

Malhat FM, Haggag MN, Loutfy NM, Osman MAM, Ahmed MT (2015) Residues of organochlorine and syntetic pyrethroid pesticides in honey, an indicator of ambient environment, a pilot study. Chemosphere 120:457-461

Meli MA, Desideri D, Roselli C, Feduzi L, Benedetti C (2016) Radioactivity in honey of the central Italy. Food Chem 201:349-355

Merighi M, Sandrini S, Landini S et al (2000) Chemiluminescent and colorimetric detection of Erwinia amylovora by immunoenzymatic determination of PCR amplicons (PCR-ELISA) from plasmid pEA29. Plant Dis 84:49-54

Mickova B, Kovalczuk T, Rauch P, Moreno MJ et al (2005) Analytical performance of validated chemiluminescnet enzyme immunoassays to detect $N$-methylcarbamate pesticides. Anal Chim Acta 528:243-248

Milivojevic T, Glavan G, Bozic J, Sepcic K, Mesaric T, Drobne D (2015) Neurotoxic potential of ingested $\mathrm{ZnO}$ nanomaterials on bees. Chemosphere 120:547-554

Niell S, Jesus F, Perez N, Perz C et al (2017) Neonicotinoids transference from the field to the hive by honey bees: towards a pesticide residues biomonitor. Sci Total Environ 581-582:25-31

Nikolić TV, Kojić D, Orčić S et al (2016) The impact of sublethal concentrations of $\mathrm{Cu}, \mathrm{Pb}$ and $\mathrm{Cd}$ on honeybee redox status, superoxide dismutase and catalase in laboratory conditions. Chemosphere 164:98-105

Panatto D, Gasparini R, Lai P, Rovatti P, Gallelli G (2007) Long-term decline of ${ }^{137} \mathrm{Cs}$ concentration in honey in the second decade after Chernobyl accident. Sci Total Environ 382:147-152

Panichev N, McCrindle RI (2004) The application of bio-indicators for the assessment of air pollution. J Environ Monit 6:121-123

Pérez N, Jesus F, Pérez C, Niell S, Draper A et al (2016) Continuous monitoring of beehives' sound for environmental pollution control. Ecol Eng 90:326-330

Perugini M, Tulini SMR, Zezza D, Fenucci S, Conte A, Amorena M (2018) Occurrence of agrochemical residues in beeswax samples collected in Italy during 2013-2015. Sci Total Environ 625:470-476

Pirk CW, Miranda JR, Kramer M, Murray TE et al (2013) Statistical guidelines for Apis mellifera research. J Apic Res 52:1-24

Pohl P, Stecka H, Sergiel I, Jamroz P (2012) Different aspects of the elemental analysis of honey by flame atomic absorption and emission spectrometry: a review. Food Anal Methods 5:737-751

POPRC (2016) Report of the Twelfth Meeting of the Persistent Organic Pollutants Review Committee. http://chm.pops.int/TheConvent ion/POPsReviewCommittee/Meetings/POPRC12/Overview/ tabid/5171/Default.aspx. Accessed 30 Mar 2020 
Porrini C, Ghini S, Girotti S, Sabatini AG, Gattavecchia E, Celli G (2002) Use of honey bees as bioindicators of environmental pollution in Italy. In: Devillers J, Pham-Delègue MH (eds) Honey bees: estimating the environmental impact of chemicals. Taylors \& Francis, London, pp 186-247

Quigley TP, Amdarnt GV, Harwood GH (2019) Honeybees as bioindicators of changing global agricultural landscapes. Curr Opin Insect Sci SI 35:132-137

Ramachandaran R, Chen TW, Cheng SM et al (2019) A review of the advanced developments of electrochemical sensors for the detection of toxic and bioactive molecules. Inorg Chem Frontiers 6:3418-3439

Rasheed T, Nabeel F, Adeel M et al (2019) Carbon nanotubes-based cues: a pathway to future sensing and detection of hazardous pollutants. J Mol Liquids 292:111425

Rodacy PJ, Bender SFA, Bromenshenk JJ, Henderson CB, Bender G (2002) The training and deployment of honeybees to detect explosives and other agents of harm. Detection and remediation technologies for mines and minelike targets VII, parts 1 and 2. Proc SPIE 4742. https://doi.org/10.1117/12.479119

Rossi S, Dalpero AP, Ghini S et al (2001) Multiresidual method for the gas chromatographic analysis of pesticides in honeybees cleaned by gel permeation chromatography. J Chromat A 905:223-232

Ruschioni S, Riolo P, Minuz RL, Stefano M, Cannella M, Porrini C, Isidoro N (2013) Biomonitoring with honeybees of heavy metals and pesticides in nature reserves of the Marche Region (Italy). Biol Trace Elem Res 154:226-233

Sabatini AG, Alessandrini A, Alexandrova M et al (2006) Relationships between Apis mellifera and Erwinia amylovora: bioindication, bacterium dispersal, and quarantine procedures. ISHS Acta Horticulturae 704: X International Workshop on Fireblight, Bologna, Italy, Feb 2006, pp 155-162

Sadegh A, Mozafari AA, Bahmani R, Shokri K (2012) Use of honeybees as bio-indicators of environmental pollution in the Kourdistan province of Iran. J Apicult Sci 56:83-88

Sajtos Z, Herman P, Harangi S, Baranyai E (2019) Elemental analysis of Hungarian honey samples and bee products by MP-AES. Microchem J 149:103968. https://doi.org/10.1016/j.micro c. 2019.103968

Sgolastra F, Medrzycki P, Bortolotti L et al (2020) Bees and pesticide regulation: lessons from the neonicotinopid experience. Biol Cons 241:108356

Shaw JA, Nugent PW, Johnson J et al (2011) Long-wave infrared imaging for non-invasive beehive population assessment. Opt Express 19:399-408

Shi L, Yin Y, Zhang L-C et al (2019) Design and engineering heterojunctions for the photoelectrochemical monitoring of environmental pollutants: a review. Appl Catal B Environ 248:405-422

Silici S, Oluozlu OL, Tuzen M, Soylak M (2013) Honeybee and honey as monitors for heavy metal contamination near the thermal power plant in Mugla, Turkey. Toxicol Ind Health 32:507-516

Simić M, Gillanders R, Avramonic A, Gajic S, et al (2019) Honeybee activity monitoring in a biohybrid system for explosive detection. Proc Int Conf on Medical and Biological Engineering CMBEBIH, Banja Luka, Bosnia and Herzegovina, 16-18 May 2019. https://doi.org/10.1007/978-3-030-17971-7_29

Skorbilowicz E, Skorbilowicz M, Ciesluk I (2018) Bees as bioindicators of environmental pollution with metals in an urban area. J Ecol Eng 19:229-234

Soler C, Girotti S, Ghini S et al (2008) Analysis of chlorpyrifos in water, fruit juices and honeybee extracts by chemiluminescent ELISA. Anal Lett 41:2539-2553

Storelli MM, Marcotrigiano GO (2005) Bioindicator organisms: heavy metal pollution evaluation in the Ionian Sea (Mediterranean Sea-Italy). Environ Monit Assess 102:159-166
Svoboda J (1961) Industrial poisoning of bees by arsenic. Ved Pr Vyzk Ustavu Vcelarskeho CSAZV 2:55-60

Svoboda J (1962) Teneur en strontium 90 dans les abeilles et dans leurs produits. Bull Apicole 5:101-103

Tonelli D, Gattavecchia E, Ghini S, Porrini C, Celli C, Mercuri AM (1990) Honey bees and their products as indicators of environmental radioactive pollution. J Radioanal Nucl Chem $141: 427-436$

Tong Z, Duan J, Wu Y, Liu Q, He Q, Shi Y, Yu L, Cao H (2018) A survey of multiple pesticide residues in pollen and beebread collected in China. Sci Total Environ 640-641:1578-1586

Totti S, Fernández M, Ghini S, Picó Y, Fini F, Mañes J, Girotti S (2006) Application of matrix solid phase dispersion to the determination of imidacloprid, carbaryl, aldicarb, and their main metabolites in honeybees by liquid chromatography-mass spectrometry detection. Talanta 69:724-729

Tuzen M, Silici S, Mendil D, Soylak M (2007) Trace element levels in honeys from different regions of Turkey. Food Chem 103:325-330

US EPA (1970) The Clear Air Act. https://www.epa.gov/laws-regul ations/summary-clean-air-act. Accessed 30 Mar 2020

US EPA (1974) The Safe Drinking Water Act. https://www.epa.gov/ laws-regulations/summary-safe-drinking-water-act. Accessed 30 Mar 2020

US EPA (2000) The Beach Act. https://www.epa.gov/laws-regulation s/summary-beach-act. Accessed 30 Mar 2020

US EPA (2007) Report on the Environment. https://cfpub.epa.gov/si/ si_public_record_report.cfm?Lab $=$ NCEA\&dirEntryId $=14091$ 7. Accessed 30 Mar 2020

US EPA (2016) The Frank R. Lautenberg Chemical Safety for the 21st Century Act. https://www.epa.gov/assessing-and-managingchemicals-under-tsca/frank-r-lautenberg-chemical-safety-21stcentury-act. Accessed 30 Mar 2020

Van der Steen JJM (2016) The colony of the honeybee (Apis mellifera L.) as a bio-sampler for pollutants and plant pathogens. PhD thesis. Wageningen University, Wageningen. http://edepot.wur. nl/375348. Accessed 30 Mar 2020

Van der Steen JJM, de Kraker J, and Grotenhuis T (2012) Spatial and temporal variation of metal concentrations in adult honeybees (Apis mellifera L.). Environ Monit Assess 184:4119-4126

Van der Steen JJM, de Kraker J, Grotenhuis T (2015) Assessment of the potential of honeybees (Apis mellifera L.) in biomonitoring of air pollution by cadmium, lead and vanadium. J Environ Protect 6:96-102

Van der Zwet T (1996) Present worldwide distribution of fire blight. Acta Horticult 411:7-8

Van der Zwet T, Beer SV (1995) Fire blight, its nature, prevention and control. A practical guide to integrated disease management. Agric Inf Bull 631:91-95

Van Meter RJ, Adelizzi R, Glinski DA et al (2019) Agrochemical mixtures and amphibians: the combined effects of pesticides and fertilizers on stress, acetylcholinesterase activity and bioaccumulation in a terrestrial environment. Environ Toxicol Chem 38:1052-1061

Warne RT (2014) A primer on multivariate analysis of variance (MANOVA) for behavioral scientists. Pract Assess Res Eval 19:1-10

Wei Y, Hen F, Xue X et al (2016) Determination of persistent environmental pollutants in bee pollen by gas chromatography-mass spectrometry using a modified QuEChERS approach. Curr Anal Chem 12:366-377

Wells K, Bradley DA (2012) A review of X-ray explosives detection techniques for checked baggage. Appl Radiat Isotopes 70:1729-1746 
Wolterbeek B (2002) Biomonitoring of trace element air pollution: principles, possibilities and perspectives. Environ Pollut 120:11-21

Yarsan E, Karaca F, Ibrahim IG, Dikmen B, Koksal A, Das YK (2007) Contents of some metals in honeys from different regions in Turkey. B Environ Contam Toxicol 79:255-258

Ye Z, Yang J, Zhong N et al (2020) Tackling environmental challenges in pollution controls using artificial intelligence: a review. Sci Total Environ 699:134279
Yücel Y, Sultanoğlu P (2012) Determination of industrial pollution effects on citrus honey with chemometric approach. Food Chem 135:170-178

Zarić NM, Deljanin I, Ilijević K et al (2018) Honeybees as sentinel of lead pollution: spatio-temporal variations and source appointment using stable isotopes and Kohonen self-organizing maps. Sci Total Environ 642:56-62 